\title{
Study and Simulation on Discrete Dynamics of Bertrand Triopoly Team-Game
}

\author{
Lijian Sun ${ }^{1,2}$ and Junhai Ma ${ }^{1}$ \\ ${ }^{1}$ Group of Nonlinear Dynamics and Chaos, College of Management and Economics, Tianjin University, Tianjin 300072, China \\ ${ }^{2}$ College of Science, Tianjin University of Science and Technology, Tianjin 300457, China \\ Correspondence should be addressed to Lijian Sun; lijians1980@163.com and Junhai Ma; mjhtju@aliyun.com
}

Received 4 December 2014; Accepted 9 February 2015

Academic Editor: Domenico Mundo

Copyright (c) 2015 L. Sun and J. Ma. This is an open access article distributed under the Creative Commons Attribution License, which permits unrestricted use, distribution, and reproduction in any medium, provided the original work is properly cited.

\begin{abstract}
A Bertrand Triopoly team-game model is considered in which two firms with bounded rational expectations make up a cooperative team and allocate common profits proportionate to their marketing strength. The existence and three-dimensional stable regions of the fixed points are investigated. Complex effects of $(\alpha, \beta, v)$ on bifurcation scenarios and profits are displayed by parameter basin plots and average profits charts. Impact of assigning weight $w$ on stable regions, 2D-bifurcation phase portraits, and the average profits is investigated. We find $(\alpha, \beta, v)$ and $w$ can cause chaos; chaos resulting from adjustment speed is harmful to all the players as for profits, while chaos resulting from $w$ is conducive to firm 3. Basins of attraction are investigated and we find that the attraction domain will become smaller with increase of price modification speed.
\end{abstract}

\section{Introduction}

An oligopoly is a market structure dominated by a few firms. The market is known as Bertrand oligopolists if firms choose price as their strategic variable to maximize their profits in an uncertain market demand. It is called a Triopoly if there are three firms in the oligopoly.

Many markets in the world have always been with Triopoly market structure. Take a telecommunication market and a petroleum market in China as examples. All the oligopolists may choose price as their competitive strategy. Price decisions by the firms in the Triopoly need to take into account the likely responses of the other players. We assume that two firms with bounded rational expectations make up a cooperative team; the third firm has adaptive expectations.

Since Rand first proposed that chaos may occur in a system of the duopoly market with the oligopolists' reaction functions, the literatures on dynamics of Bertrand game model are very rich in economics. Bester [1] studied the stability of price competition in a horizontally differentiated duopoly. Zhang et al. [2] investigated the complexity of price competition in a Bertrand model with bounded rationality and found that if the speed of adjustment of bounded rational player increased, the stability of the Nash equilibrium point may change and bifurcation and chaos would occur. Peng et al. [3] considered the competition of a Bertrand model with delayed bounded rationality and pointed out that lagged structure may expand the stable region or change the system's chaotic state into stable state. $\mathrm{Ma}$ and $\mathrm{Wu}$ [4] analyzed the influence of delayed decision on the stability of a Triopoly price game model and found that the number of time delay decision makers cannot improve the system stability. Fanti et al. [5] investigated the dynamics of a Bertrand duopoly with differentiated products and found that if the product differentiation between the firms increased, the interior fixed point would be unstable and attractors would have a complex structure. Zhao et al. [6] considered pricing decisions for two substitutable products in a supply chain and analyzed the effects of manufacturers' different competitive strategies on the optimal pricing decisions. Giri and Sharma [7] studied a two-echelon supply chain with advertising cost dependent demand. Results showed that it was always beneficial for the manufacturer to adopt different wholesale pricing strategy for the retailers.

In a real market, the coexistence of competition and cooperation makes the team composed of similar companies 
in order to get the maximum profits. The Renault-Nissan Alliance is one of the most successful cases. Both sides share the product design and the production platform and thereby reduce their production costs and improve asset utilization. In China, in order to deal with the fierce competition, Chery Automobile and GAC build the first domestic strategic alliance in auto industry. They both hope to reduce costs by cooperation and gain more profits.

In recent years, some scholars have studied the team competition model which has the features of bounded rationality. Ahmed and Hegazi [8] studied the vendors in the same team to make production strategy in accordance with the outputs of the team as a whole. Elettreby and Hassan [9] proposed two different versions of the multiteam model where a team of two firms competes with another team and studied the equilibrium solutions, the conditions of their local asymptotic stability. Ding et al. [10] proposed a Cournot game model and showed that chaos may occur with changing of the profit weighting coefficients and the adjustment rate of boundedly rational players in the cooperative team.

The literatures [8-10] showed the complex dynamics of the team competition model, but they did not show influence of chaos on profits of all the players. What is the impact of chaos on the profits of the players?

This paper mainly discusses the dynamic and repeated games among different competitors by considering the complex influence of parameters $(w$ and $(\alpha, \beta, v))$ on the game process and the influences which assigning weight $w$ and $(\alpha, \beta, v)$ have on the profits. Theoretical analysis and numerical simulations of the system are made in detail.

The paper is organized as follows. In Section 2, a Bertrand Triopoly model with team-game is established. In Section 3, the existence and local stability of equilibrium points about parameters $\alpha, \beta, v$ are discussed. Complex influence of $(\alpha, \beta, v)$ on bifurcation scenarios and profits are investigated in Section 4. The effects of assigning weight on stable regions, profits, and prices are shown in Section 5 using parameter basin plots [11, 12]. Basins of attraction [13] are given in Section 6. At last, three conclusions are made.

(1) If the strength difference of the team firms is too large, the market will be easy to fall into chaos. Chaos resulting from $w$ is conducive to firm 3 .

(2) With increase of price modification speed, the system will lose stability. The firm in the cooperative team who has a more assigning weight should pay more attention to control the speed of price adjustment. Chaos resulting from adjustment speed is harmful to all the players.

(3) Team firms' price must be kept within a certain range to keep the market stable.

\section{The Bertrand Triopoly Game Model}

We consider a Bertrand Triopoly game in which the price and the demand of firm $i$ 's product are denoted by $p_{i}(t)$ and $q_{i}(t)$, respectively, $i=1,2,3$. Firm 1 and firm 2 in the Triopoly make up a cooperative team and have the same cost of production $c_{1}=c_{2}$, as they share the same production technology. They allocate common interests proportionate to the assigning weights $w$ and $1-w(0 \leq w \leq 1)$ which reflect the strength difference between the two firms. Based on the classic Bertrand model, the demand functions for the three firms are as follows:

$$
\begin{aligned}
& q_{1}(t)=a_{1}-b_{1} p_{1}(t)+r_{1} p_{2}(t)+s_{1} p_{3}(t), \\
& q_{2}(t)=a_{2}-b_{2} p_{2}(t)+r_{2} p_{1}(t)+s_{2} p_{3}(t), \\
& q_{3}(t)=a_{3}-b_{3} p_{3}(t)+r_{3} p_{1}(t)+s_{3} p_{2}(t)
\end{aligned}
$$

in which $a_{i}, b_{i}, r_{i}, s_{i}(i=1,2,3)$ are all positive constants and $b_{i}, r_{i}, s_{i}$ denote the mutual product substitution rates among three different firms. Assume that all the three firms have linear cost functions

$$
C_{i}\left(q_{i}\right)=c_{i} q_{i}, \quad i=1,2,3 .
$$

Hence, the profits functions of firms in period $t$ are given by

$$
\begin{aligned}
\pi_{1}(t)= & \left(p_{1}(t)-c_{1}\right)\left(a_{1}-b_{1} p_{1}(t)+r_{1} p_{2}(t)+s_{1} p_{3}(t)\right), \\
\pi_{2}(t)= & \left(p_{2}(t)-c_{1}\right)\left(a_{2}-b_{2} p_{2}(t)+r_{2} p_{1}(t)+s_{2} p_{3}(t)\right), \\
\pi_{3}(t)= & \left(p_{3}(t)-c_{3}\right)\left(a_{3}-b_{3} p_{3}(t)+r_{3} p_{1}(t)+s_{3} p_{2}(t)\right), \\
\pi_{A}(t)= & w \pi_{1}(t)+(1-w) \pi_{2}(t) \\
= & w\left(p_{1}(t)-c_{1}\right)\left(a_{1}-b_{1} p_{1}(t)+r_{1} p_{2}(t)+s_{1} p_{3}(t)\right) \\
& +(1-w)\left(p_{2}(t)-c_{1}\right) \\
& \cdot\left(a_{2}-b_{2} p_{2}(t)+r_{2} p_{1}(t)+s_{2} p_{3}(t)\right)
\end{aligned}
$$

in which $\pi_{i}(t)$ is the profits of firm $i$ and $\pi_{A}(t)$ is the profits of the cooperative team.

So the firms can get their maximum profit by the following marginal profits functions:

$$
\begin{aligned}
\frac{\partial \pi_{A}(t)}{\partial p_{1}(t)}= & w\left(a_{1}-2 b_{1} p_{1}(t)+r_{1} p_{2}(t)+s_{1} p_{3}(t)+c_{1} b_{1}\right) \\
& +(1-w)\left(p_{2}(t)-c_{1}\right) r_{2}, \\
\frac{\partial \pi_{A}(t)}{\partial p_{2}(t)}= & w r_{1}\left(p_{1}(t)-c_{1}\right)+(1-w) \\
& \cdot\left(a_{2}-2 b_{2} p_{2}(t)+r_{2} p_{1}(t)+s_{2} p_{3}(t)+c_{1} b_{2}\right),
\end{aligned}
$$

$$
\frac{\partial \pi_{3}(t)}{\partial p_{3}(t)}=a_{3}-2 b_{3} p_{3}(t)+r_{3} p_{1}(t)+s_{3} p_{2}(t)+c_{3} b_{3} .
$$

While, in practice, they may do not know other firm's price in the next-period in advance, they cannot calculate their optimal prices by the marginal profits functions above. We consider the two firms of the cooperative team bounded rational players and their next-period price decision is on the basis of the local estimate to their marginal profits in current 
period. This means that if the marginal profits of the current period are positive, the firm will raise their prices in the next period; otherwise, they will reduce their prices. So firm 1 and firm 2 adopt their strategies in the following form:

$$
\begin{aligned}
& p_{1}(t+1)=p_{1}(t)+\alpha p_{1}(t) \frac{\partial \pi_{A}(t)}{\partial p_{1}(t)} \\
& p_{2}(t+1)=p_{2}(t)+\beta p_{2}(t) \frac{\partial \pi_{A}(t)}{\partial p_{2}(t)}
\end{aligned}
$$

where $\alpha$ and $\beta(0<\alpha<1,0<\beta<1)$ denote the first two players' price adjustment speed, respectively. We assume that the third firm has adaptive expectations; that is, they take current period's price $p_{3}(t)$ and the naïve expectations $p_{3}^{*}(t)$ into consideration when they decide the price $p_{3}(t+1)$. This means that the third firm considers the expectation about the price before and foresees other firm's price decision. The proportion is given by $1-v$ and $v(v \in[0,1])$ that regulates how reluctant the third player is to change its price in the $t$ th period. firm is

Let $\partial \pi_{3}(t) / \partial p_{3}(t)=0$; the naïve expectations of the third

$$
p_{3}^{*}(t)=\frac{\left(a_{3}+r_{3} p_{1}(t)+s_{3} p_{2}(t)+b_{3} c_{3}\right)}{\left(2 b_{3}\right)}
$$

So the dynamic equation of third player is given by

$$
\begin{aligned}
p_{3}(t+1)= & (1-v) p_{3}(t) \\
& +\frac{v\left(a_{3}+r_{3} p_{1}(t)+s_{3} p_{2}(t)+b_{3} c_{3}\right)}{\left(2 b_{3}\right)} .
\end{aligned}
$$

Hence, the dynamic Bertrand Triopoly game in this case is formed from combining (4), (5), (7), and (9). Then, the dynamic system with team-game is described by

$$
\begin{aligned}
p_{1}(t+1)= & p_{1}(t)+\alpha p_{1}(t) \\
\cdot[ & w\left(a_{1}-2 b_{1} p_{1}(t)+r_{1} p_{2}(t)+s_{1} p_{3}(t)+c_{1} b_{1}\right) \\
& \left.+(1-w)\left(p_{2}(t)-c_{1}\right) r_{2}\right],
\end{aligned}
$$

$$
\begin{aligned}
p_{2}(t+1)= & p_{2}(t)+\beta p_{2}(t) \\
& \cdot\left[w r_{1}\left(p_{1}(t)-c_{1}\right)+(1-w)\right. \\
& \left.\cdot\left(a_{2}-2 b_{2} p_{2}(t)+r_{2} p_{1}(t)+s_{2} p_{3}(t)+c_{1} b_{2}\right)\right] \\
p_{3}(t+1)= & (1-v) p_{3}(t) \\
+ & \frac{v\left(a_{3}+r_{3} p_{1}(t)+s_{3} p_{2}(t)+b_{3} c_{3}\right)}{\left(2 b_{3}\right)} .
\end{aligned}
$$

\section{Equilibrium Points and Local Stability about Price Adjustment Speed}

According to system (10), let $p_{i}(t+1)=p_{i}(t)$; then three boundary equilibria

$$
\begin{aligned}
& E_{1}=\left(0,0, \frac{a_{3}+b_{3} c_{3}}{2 b_{3}}\right), \\
& E_{2}=\left(0, p^{22}, p^{23}\right), \\
& E_{3}=\left(p^{31}, 0, p^{33}\right)
\end{aligned}
$$

and unique Nash equilibrium point

$$
E_{4}=\left(p_{1}^{*}, p_{2}^{*}, p_{3}^{*}\right)
$$

can be obtained.

Boundary equilibria $E_{i}(i=1,2,3)$ mean that at least one firm will be out of the market, while the Nash equilibrium point means that all the firms can survive $\left(p_{1}^{*}, p_{2}^{*}, p_{3}^{*}\right.$ must be positive).

Values of parameters in (10) (such as $\alpha, \beta, v$ ) may affect the stability of the equilibrium points. So it is meaningful to study stability of the preceding equilibrium points about $\alpha, \beta, v$.

In order to analyze the stability of the preceding equilibrium points, the Jacobian matrix for discrete dynamic system (10) is found as follows:

$$
J=\left(\begin{array}{ccc}
J_{1} & \alpha p_{1}^{*}\left(r_{1} w+r_{2}(1-w)\right) & \alpha s_{1} w p_{1}^{*} \\
\beta p_{2}^{*}\left(w r_{1}+(1-w) r_{2}\right) & J_{2} & \beta p_{2}^{*}(1-w) s_{2} \\
\frac{r_{3} v}{2 b_{3}} & \frac{s_{3} v}{2 b_{3}} & 1-v
\end{array}\right)
$$

in which

$$
\begin{gathered}
J_{1}=1+\alpha\left[w\left(a_{1}-4 b_{1} p_{1}^{*}+r_{1} p_{2}^{*}+s_{1} p_{3}^{*}+c_{1} b_{1}\right)\right. \\
\left.+(1-w)\left(p_{2}^{*}-c_{1}\right) r_{2}\right] \\
J_{2}=1+\beta\left[w r_{1}\left(p_{1}^{*}-c_{1}\right)+(1-w)\right. \\
\left.\cdot\left(a_{2}-4 b_{2} p_{2}^{*}+r_{2} p_{1}^{*}+s_{2} p_{3}^{*}+c_{1} b_{2}\right)\right] .
\end{gathered}
$$

Remark 1. $E_{1}$ is an unstable equilibrium point when $w>$ $2 b_{3} c_{1} r_{2} /\left(2 b_{3}\left(a_{1}+c_{1} b_{1}+c_{1} r_{2}\right)+s_{1} a_{3}+b_{3} c_{3} s_{1}\right)$.

Proof. At point $E_{1}$,

$$
J_{1}=1+\alpha\left[w\left(a_{1}+s_{1} \frac{a_{3}+b_{3} c_{3}}{2 b_{3}}+c_{1} b_{1}\right)-(1-w) c_{1} r_{2}\right]
$$


is an eigenvalue corresponding to $E_{1}$; then if $w>2 b_{3} c_{1} r_{2} /$ $\left(2 b_{3}\left(a_{1}+c_{1} b_{1}+c_{1} r_{2}\right)+s_{1} a_{3}+b_{3} c_{3} s_{1}\right)$, then $J_{1}>1$, and $E_{1}$ is an unstable equilibrium point.

From an economic point of view, if there is a great strength difference between firm 1 and firm 2, the market will be unstable.

Remark 2. $E_{2}$ and $E_{3}$ are unstable equilibrium points.

Proof. As for $E_{2}$,

$$
\begin{gathered}
J_{1}=1+\alpha\left[w\left(a_{1}+r_{1} p^{22}+s_{1} p^{23}+c_{1} b_{1}\right)\right. \\
\left.+(1-w)\left(p^{22}-c_{1}\right) r_{2}\right]
\end{gathered}
$$

is the eigenvalue corresponding to $E_{2}$. At point $E_{2}$, the price of the product provided by firm 1 is 0 , so firm 1 is out of the market; if $E_{2}$ is a stable equilibrium point, then firm 2 must survive in the market, then $p^{22}-c_{1}>0$, and then $J_{1}>1$, so $E_{2}$ is an unstable equilibrium point. In the same way we can prove that $E_{3}$ is an unstable equilibrium point.

From an economic point of view, if one firm in the cooperative team withdraws from the market, the market will be unstable.

While stability of the Nash equilibrium point $E_{4}$ is affected by parameters $\alpha, \beta, v$, according to Routh-Hurwitz condition, the necessary and sufficient condition of asymptotic stability at $E_{4}$ is that all the eigenvalues are inside the unit circle in complex plane. So it must satisfy the following conditions:

$$
\begin{gathered}
f(1)=1+A+B+C>0, \\
-f(-1)=1-A+B-C>0, \\
C^{2}-1<0, \\
\left(1-C^{2}\right)^{2}-(B-A C)^{2}>0,
\end{gathered}
$$

where $f(\lambda)=\lambda^{3}+A \lambda^{2}+B \lambda+C=0$ is the characteristic polynomial at $E_{4}$.

In order to show the three-dimensional stable regions, we set the parameters

$$
\begin{aligned}
a_{1}=7, & a_{2}=4, & a_{3}=6, \\
b_{1}=1.7, & b_{2}=1.3, & b_{3}=1.5, \\
r_{1}=0.4, & r_{2}=0.4, & r_{3}=0.3, \\
s_{1}=0.3, & s_{2}=0.3, & s_{3}=0.3, \\
w=0.45, & c_{1}=0,5, & c_{3}=0.6 .
\end{aligned}
$$

According to the parameters above,

$$
E_{4}=(3.2738,2.9788,2.9253) \text {. }
$$

Its Jacobian matrix is

$$
J\left(E_{4}\right)=\left(\begin{array}{ccc}
1.0-5.01 \alpha & 1.31 \alpha & 0.44 \alpha \\
1.19 \beta & 1.0-4.26 \beta & 0.49 \beta \\
0.1 v & 0.1 v & 1-v
\end{array}\right) .
$$

The characteristic equation of Jacobian matrix (20) is

$$
f(\lambda)=\lambda^{3}+A_{1} \lambda^{2}+B_{1} \lambda+C_{1}=0
$$

in which

$$
\begin{aligned}
A_{1}= & 5 \alpha+4.26 \beta+v-3.0 \\
B_{1}= & (v-1)(5.0 \alpha+4.26 \beta-2.0) \\
& -1.56 \alpha \beta-0.04 \alpha v-0.05 \beta v \\
& +(4.26 \beta-1.0)(5.0 \alpha-1.0) \\
C_{1}= & -0.1 v(0.527 \alpha \beta-0.49 \beta(4.26 \beta-1.0)) \\
& -(0.044 \alpha v+0.049 \beta v)(5 \alpha+4.26 \beta-2.0) \\
& -0.1 v(0.64 \alpha \beta-0.44 \alpha(5.0 \alpha-1.0))-(v-1.0) \\
& \cdot(1.566 \alpha \beta-(4.26 \beta-1.0)(5 \alpha-1.0)) .
\end{aligned}
$$

As can be shown in Figure 1, a stable region in the space of $(\alpha, \beta, v)$ is determined by the above inequalities. It means that if the value of $(\alpha, \beta, v)$ is in the stable region, $E_{4}$ is stable, and if the value of $(\alpha, \beta, v)$ is out of the stable region, $E_{4}$ is unstable.

In the stable region, the final prices of the three oligopolists will stay stable at $E_{4}$ after a number of games. From Figure 1, we can see that the market is stable when $v \in[0,1]$ and the values of $\alpha, \beta$ are small, but the market may be unstable when $\alpha, \beta$ increase.

The economic meaning of the stable region is that if the value of $(\alpha, \beta, v)$ is in the stable region, prices of three firms $p_{1}, p_{2}, p_{3}$ will achieve the Nash equilibrium price after a number of games. Firm 1 and firm 2 should control their price adjustment speed to maintain the market stable.

\section{A Further Investigation on Effects of $(\alpha, \beta, v)$ on the System}

4.1. Complex Effects of $(\alpha, \beta, v)$ on Bifurcation Scenarios. In order to have a further investigation about the impact of the parameters on the bifurcation scenarios, parameter basin plots are displayed. Parameter basin plots are powerful tools in the numerical analysis [12]. In this section, parameter basin plots including 2D-bifurcation phase portrait and double largest Lyapunov exponent (DLLE) are used to analyze the effects of firms' adjustment speed on system stability.

In the 2D-bifurcation phase portrait, bifurcation scenarios and route to chaos can be displayed more clearly. We choose the same values above in (18) and let $w=0.45$ and let $v=0.5$; then according to the determinant conditions of bifurcations [13], $(\alpha, \beta)$ bifurcation phase portrait is shown in Figure 2. Different colors in the $2 \mathrm{D}$ parameter space represent different states of the system. If the value of $(\alpha, \beta)$ is in period- $i$ region, system (10) will fall into a $i$-period cycle after iteration. For example, $(\alpha, \beta)=(0.45,0.3)$ is in a period-2 stable cycle, so $\left(p_{1}, p_{2}, p_{3}\right)$ will oscillate between two points at last.

In Figure 2, different colors are assigned to each region to show the particular behavior of the system (10), that is, brown, 


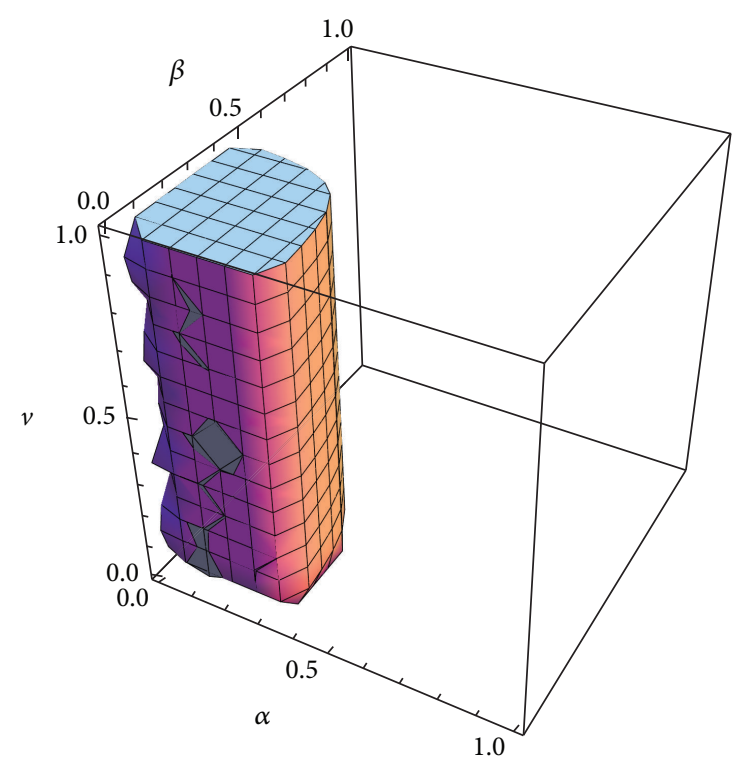

FIGURE 1: The stable region of the Nash equilibrium point, $w=0.45$.

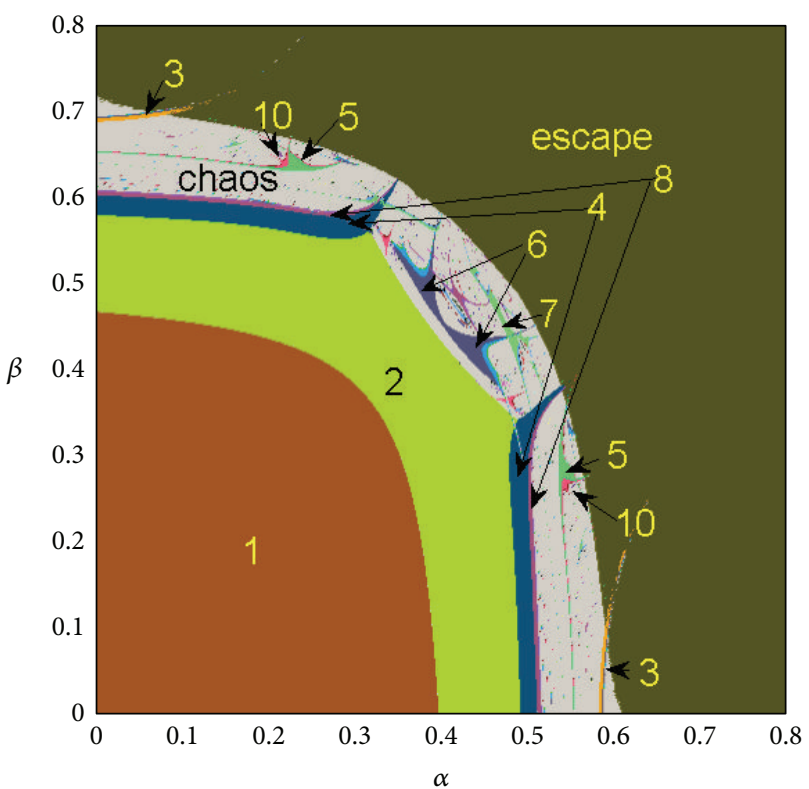

FIGURE 2: $(\alpha, \beta)$-bifurcation phase portrait $v=0.5$.

stable states; yellow, period-2 cycles; orange, period-3; blue, period-4; light green, period-5; dark gray, period-6; purple, period-8; light gray, chaotic state or quasiperiodic state; army green, escape.

In the 2D-bifurcation phase portrait, the system exhibits a sequence of flip bifurcations to chaos (which means the market will fall into chaos) then to divergence at last (which means the players will be out of the market).

In Figure $2, \alpha \in[0,0.8], \beta \in[0,0.8]$, and $v=0.5$; the system exhibits a sequence of flip bifurcations to chaos. An approximate symmetrical structure is shown because difference between assigning weights of the two firms is little.

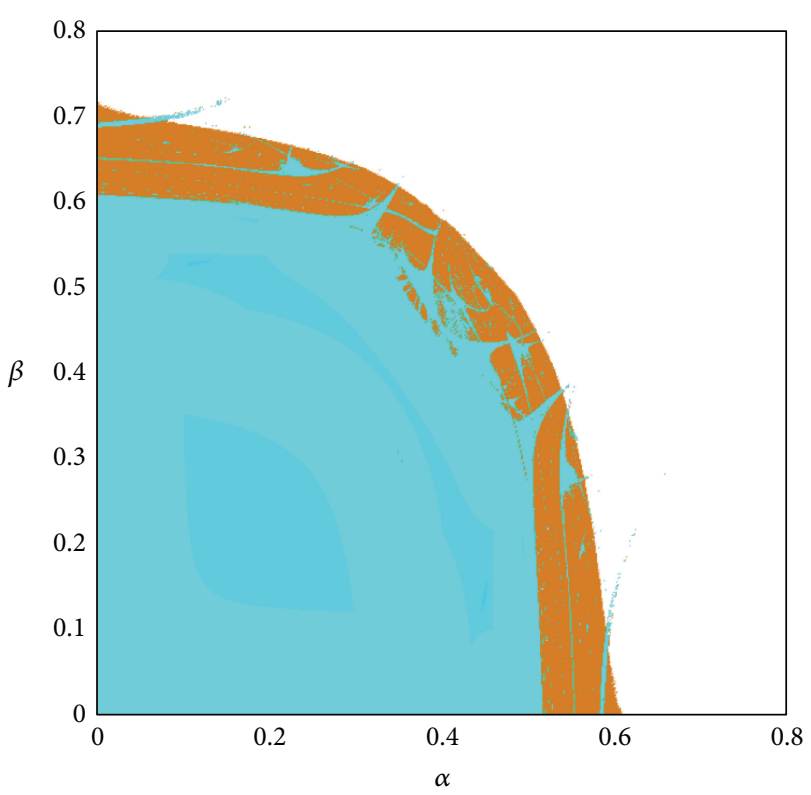

FIGURE 3: Double largest Lyapunov exponent with $(\alpha, \beta), v=0.5$.

In addition, in the chaotic region, the system contains cycle parameters islands which has the self-similar structure such as the region period-5 and period-10. There are also a lot of sets of points scattered in the light gray region.

As seen from Figure 2, if the team members' adjustment speed is relatively slow (in the brown area), the economic system will be in a steady state. Along with the increase of the adjustment speed parameters, the economic system will experience cyclical shocks, chaos, and even disappearance. Obviously, relatively larger parameters are detrimental to the economic system.

The corresponding double largest Lyapunov exponent (DLLE) with $(\alpha, \beta)$ is shown in Figure 3, in the red areas, and the largest Lyapunov exponent (LLE) $>0$. It means chaos. In the blue areas, the largest Lyapunov exponent (LLE) $<0$; with color changing from light blue to dark blue, LLE becomes smaller. We can see the trend that the system enters chaos from the perspective of DLLE.

If $\alpha$ is fixed at 0.3 in Figure 2, we can get the bifurcation diagrams with $\beta$ in Figure 4 in which blue set of points denotes $p_{1}(t)$, red set of points denotes $p_{2}(t)$, and black set of points denotes $p_{3}(t)$. As can be seen, system (10) loses its stability at $\beta=0.38$, and after a series of flip bifurcations, it falls into chaos when $\beta=0.58$. The corresponding largest Lyapunov exponent (LLE) is consistent with Figure 3.

According to Figure 4, when $\alpha=0.3, \beta=0.6$, and LLE is positive, then the system (10) is in chaos, and the chaotic attractor is shown in Figure 5.

If $\alpha$ is fixed at 0.4 in Figure 2, then we can get the bifurcation diagrams with $\beta$ in Figure 6. As can be seen, system (10) is in a 2-period cycle when $\beta<0.433$, and system (10) enters chaos through Neimark-Sacker bifurcation. Figure 6 shows the bifurcation diagrams of system (10) for $\alpha=0.4$, $v=0.5$, and $\beta$ varies from 0 to 0.6 , and the corresponding LLE is shown Figure 6. 

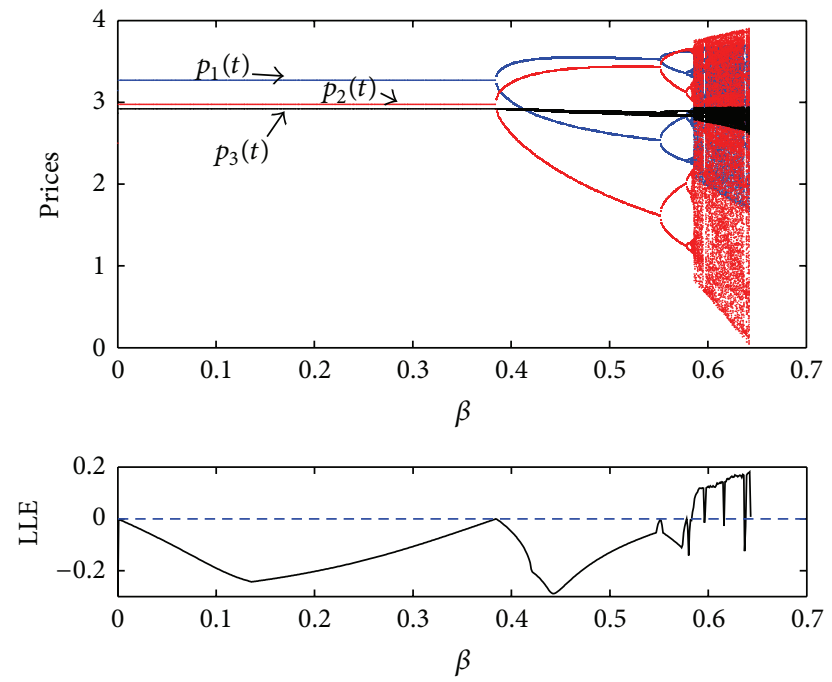

FIGURE 4: Bifurcation diagram and the largest Lyapunov exponent with $\beta, \alpha=0.3$, and $v=0.5$.

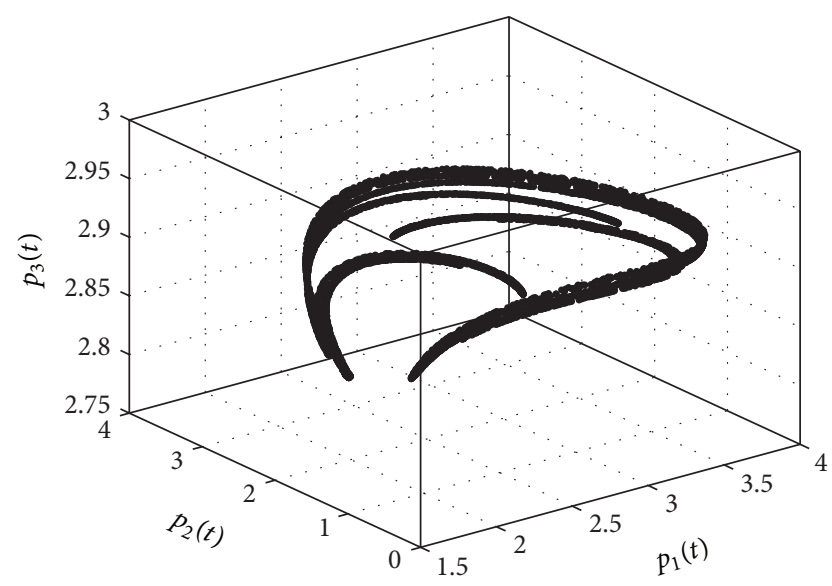

FIGURE 5: The chaotic attractor of system with $\alpha=0.3, \beta=0.6$, and $v=0.5$.
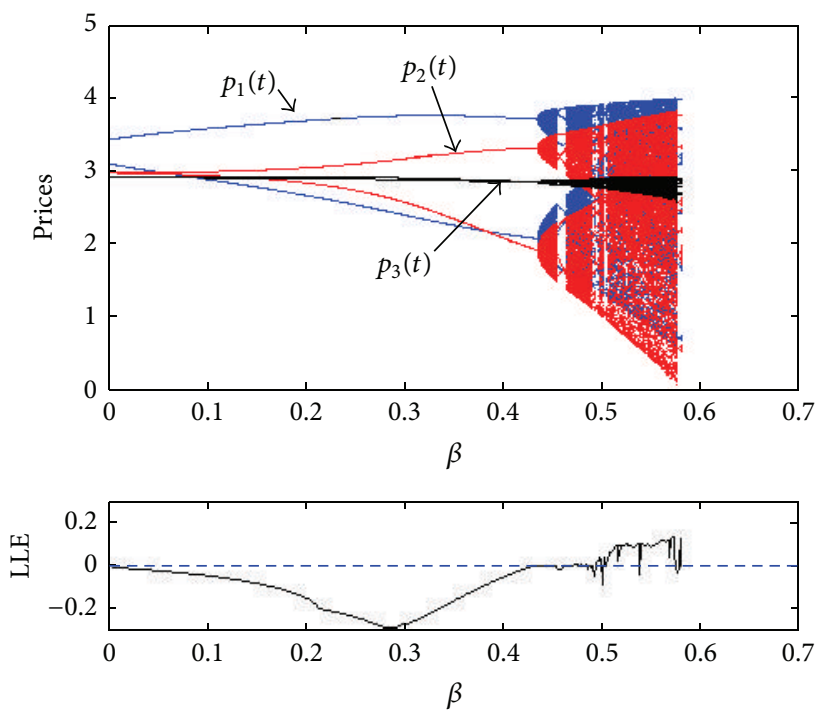

FIGURE 6: Bifurcation diagram and the largest Lyapunov exponent with $\beta, \alpha=0.4$, and $v=0.5$.

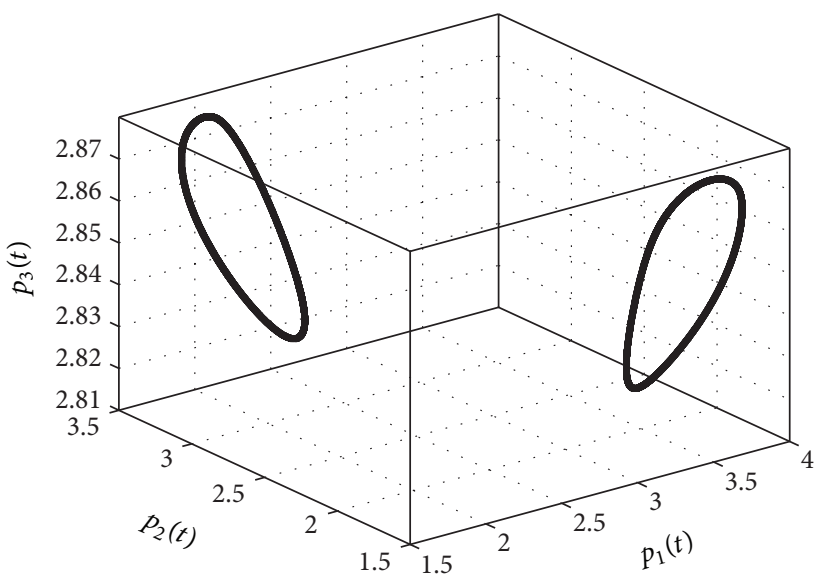

FIGURE 7: The phase space diagrams of system (10) for $\alpha=0.4, \beta=$ 0.45 , and $v=0.5$.

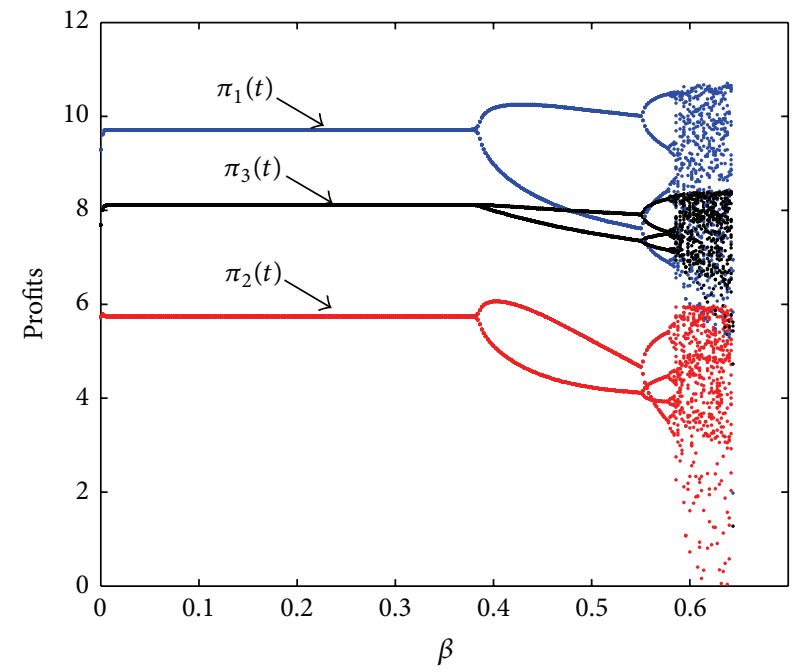

Figure 8: Profits bifurcation diagram with $\beta, \alpha=0.4$, and $v=0.5$.

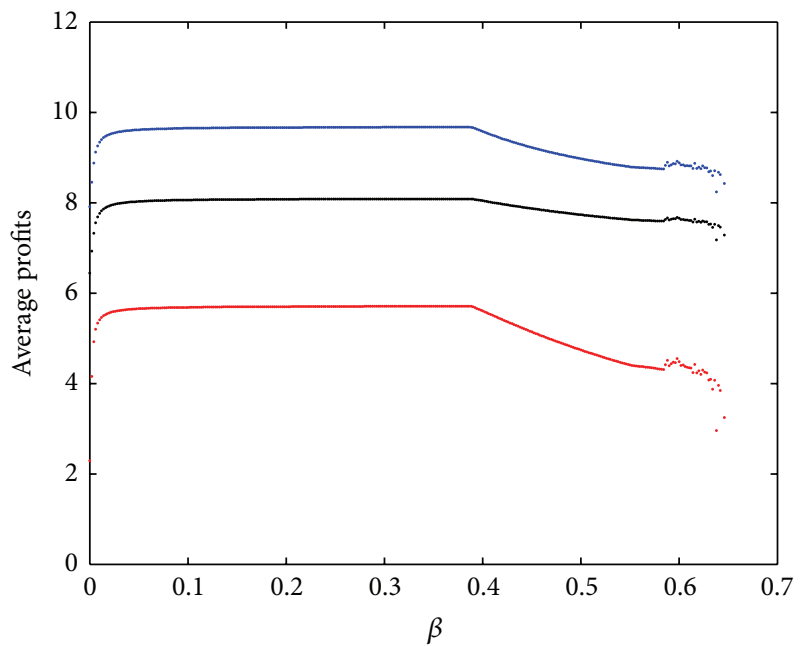

FIGURE 9: Average profits with $\beta, \alpha=0.4$, and $v=0.5$. 


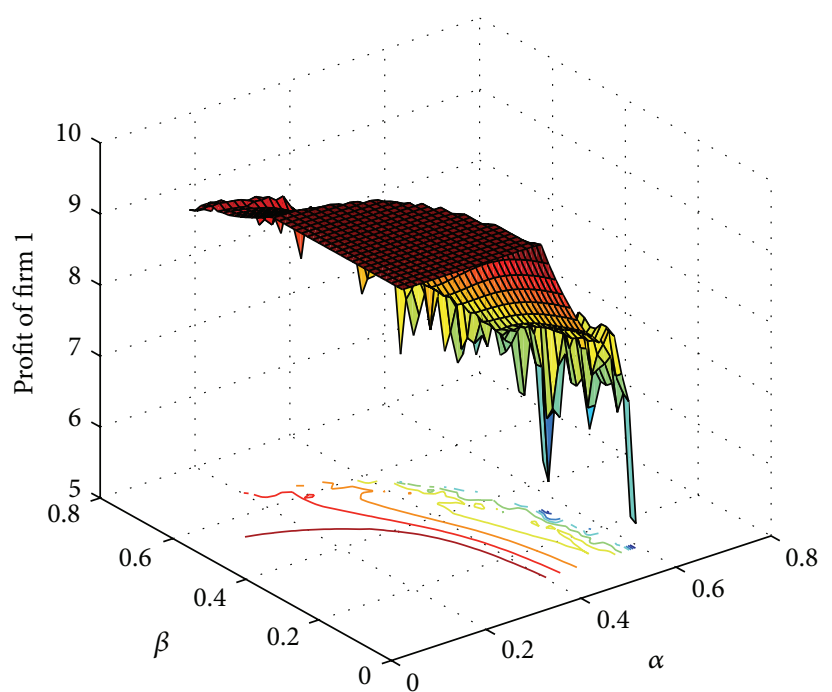

(a)

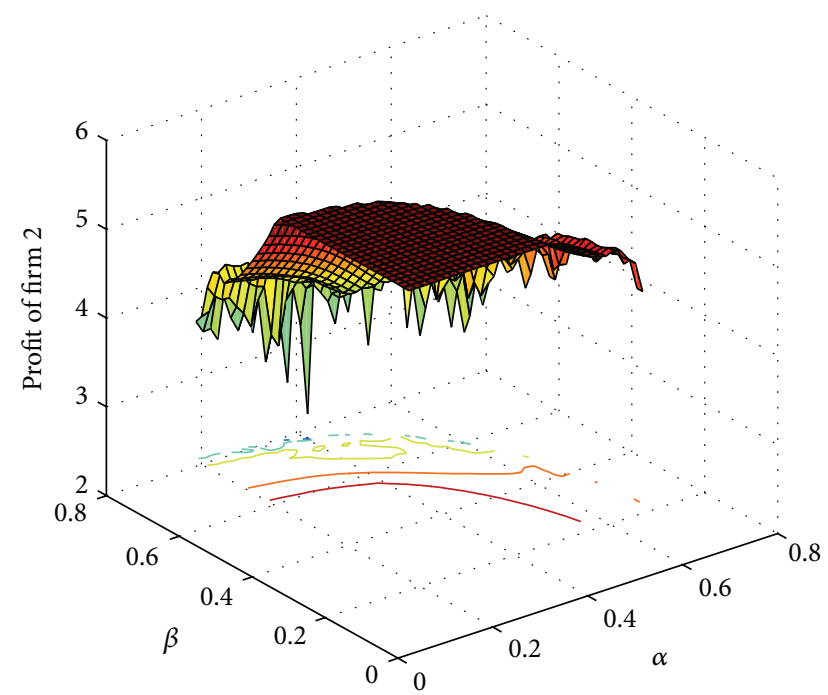

(b)

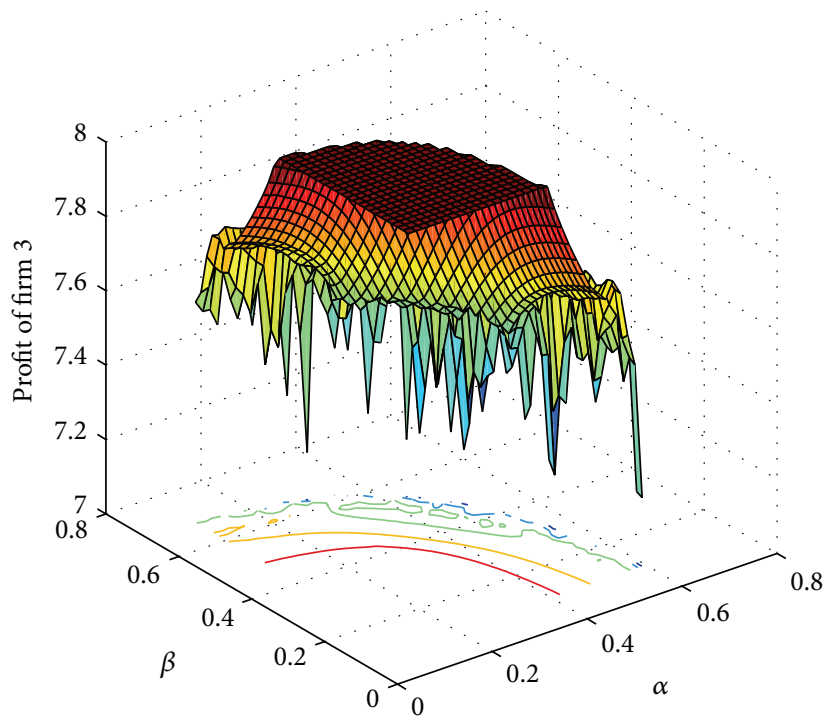

(c)

Figure 10: (a) Average profits of firm 1. (b) Average profits of firm 2. (c) Average profits of firm 3.

Figure 7 gives the phase space diagrams of system (10) for $\alpha=0.4, \beta=0.45$, and $v=0.5$; limit cycles appear. With the increase of $\beta$, the cycles are destroyed, and a strange attractor is developed.

4.2. The Effects of Adjustment Speed on Profits. Through the above analysis in Section 4.1, we find that the adjustment speed parameters determine the state of the system (stable state, period-doubling state, or chaos and so on). Moreover, the profits are different when the system is in different states. As we know, if the adjustment speed is in the stable region, the prices will reach the Nash equilibrium prices according to Section 4.1, so the profits will reach the Nash equilibrium profits. But if the adjustment speed is in the unstable region, what could profits be, especially in the chaotic region? In this subsection, we will discuss effects of adjustment speed on the profits in all different states.

Figures 8 and 9 show the profits bifurcation diagrams and average profits about adjustment speed. 3D Figures 10(a)10 (c) show the average profits of all the players in 100 games when the system is in different periods.

In Figure 8 , when $\beta<0.38$, as can be seen, profits are stable. When $\beta=0.38$, a flip bifurcation occurs and the system loses stability, followed by the chaos.

In Figure 9, average profits decrease with increase of $\beta$. We can see the same results in Figure 10.

We can conclude that higher adjustment speed is not good for players as for average profits. The team members must control their price adjustment speed in the stable region to ensure the stability of the system to maximize their profits. 


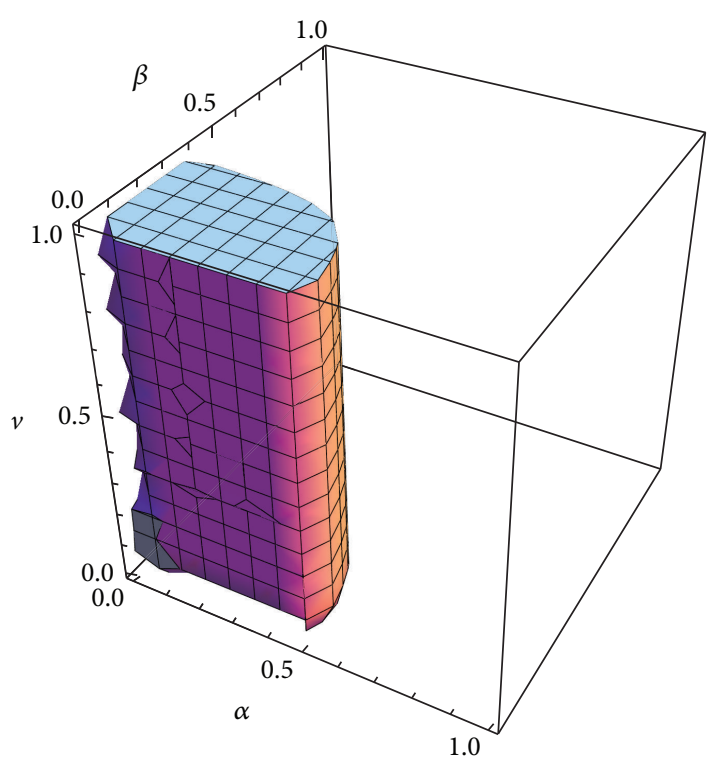

FIGURE 11: The stable region of the Nash equilibrium point, $w=0.35$.

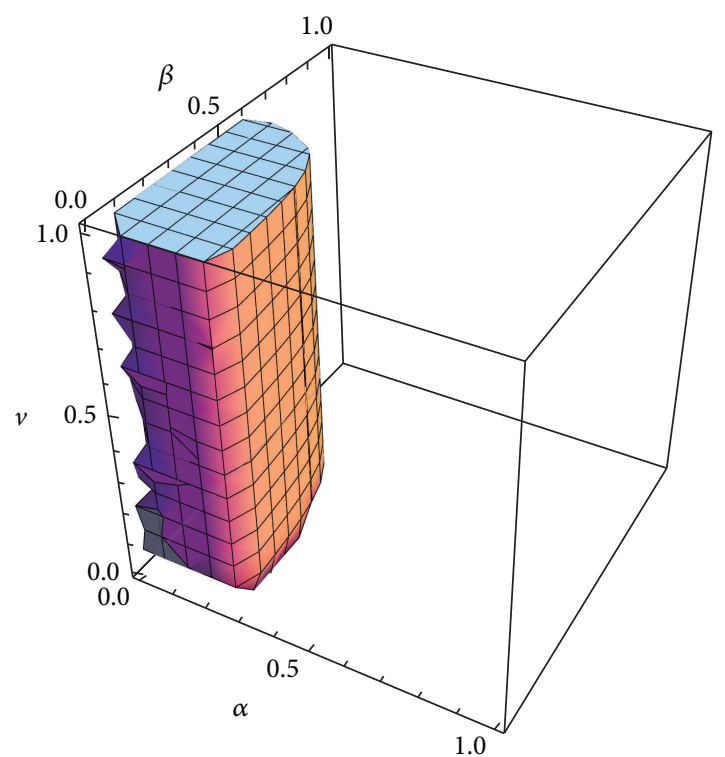

FIgURE 12: The stable region of the Nash equilibrium point, $w=$ 0.55 .

\section{The Effects of Assigning Weight on the System}

5.1. Effects of Parameter $w$ on Stable Regions and 2D-Bifurcation Phase Portraits. In order to analyze the effects of parameter $w$ on stable regions, let $w=0.35$ and 0.55 , respectively; then the corresponding stable regions are shown in Figures 11 and 12 . From the comparison, we find that, with increase of $w$, in the stable region, the range of $\beta$ expands while the range of $\alpha$ narrows.

From an economic point of view, the firm in the cooperative team who has a more assigning weight should pay more attention to control the speed of price adjustment, because

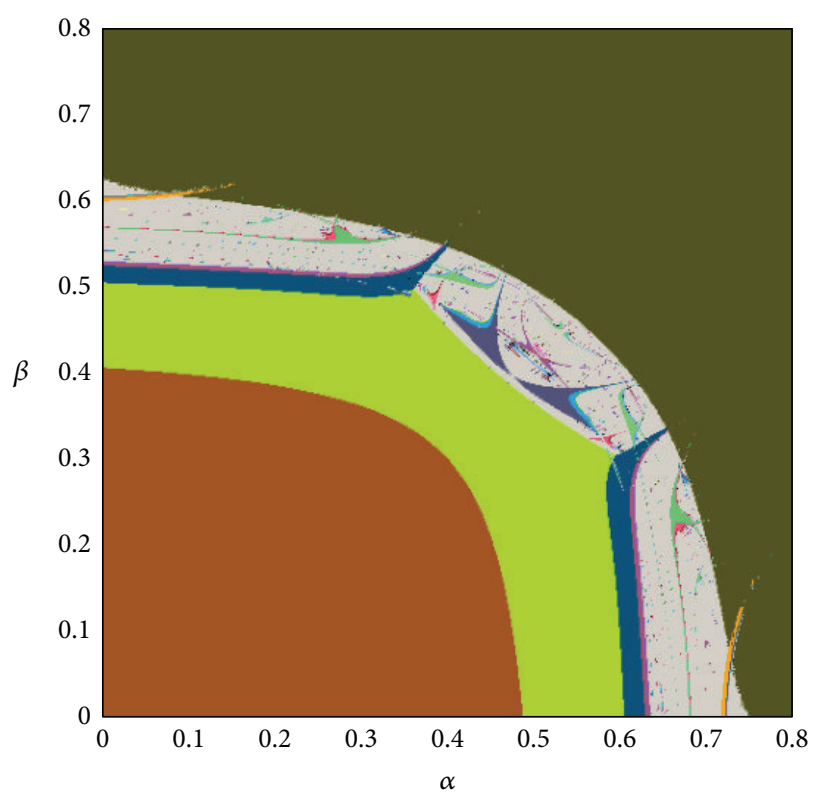

FIgURE 13: $(\alpha, \beta)$-bifurcation phase portrait, $w=0.35$.

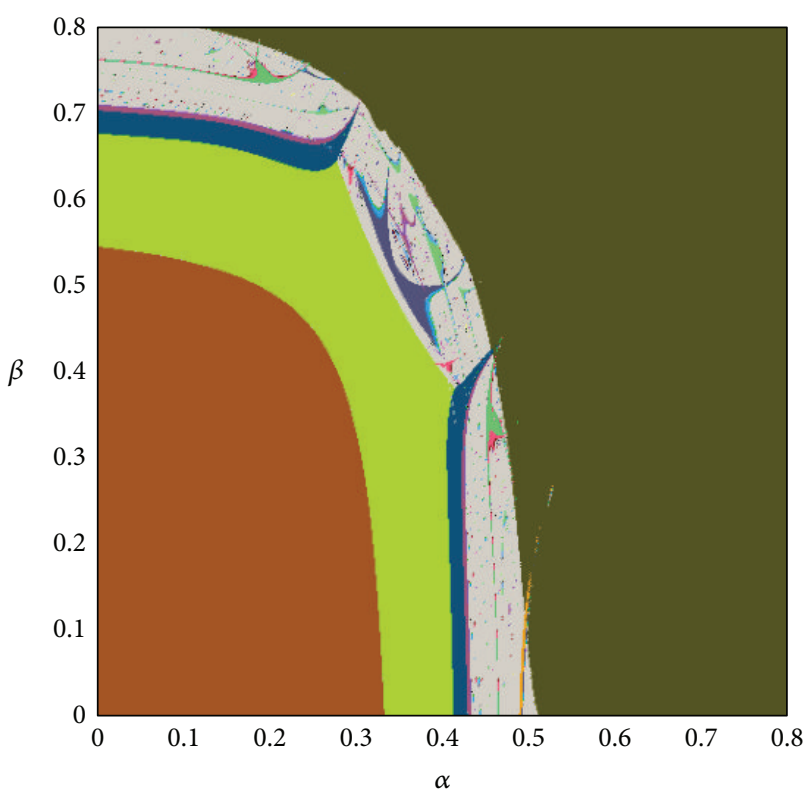

FIGURE 14: $(\alpha, \beta)$-bifurcation phase portrait, $w=0.55$.

their adjustment interval is smaller than the other's. That means if the firm in the team is stronger than the other firm in the cooperative team, their range of price adjustment speed must be smaller in order to maintain the market stable. As for the third firm who has adaptive expectations, their reluctant parameter $v$ has little effects on the stable region.

In Figures 13 and 14, $w=0.35$ and $w=0.55$, respectively; from the comparison of Figures 2, 13, and 14, we find that, with increase of $w$, in the regions except stable state and escape state, the range of $\beta$ expands and the range of $\alpha$ narrows with increase of $w$, which are consistent within the stable region. 


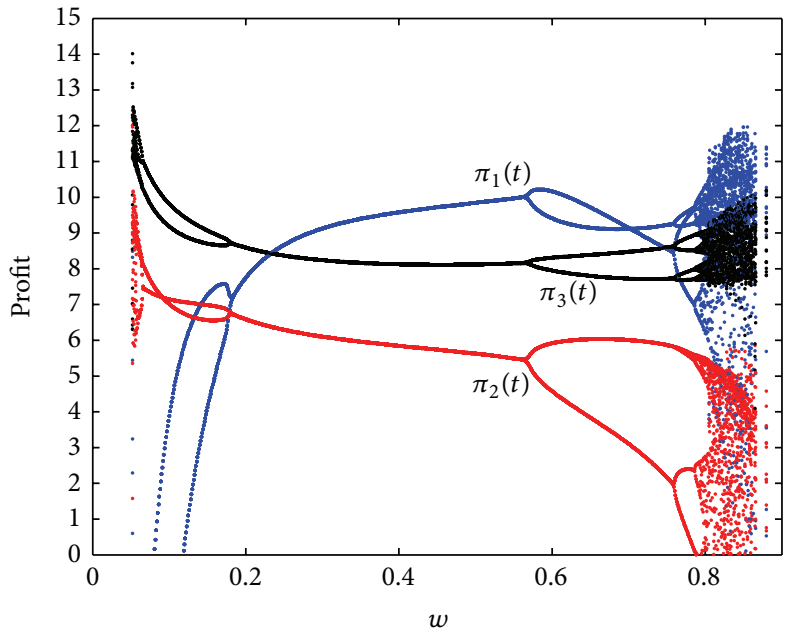

FIGURE 15: Effects of assigning weight $w$ on profits.

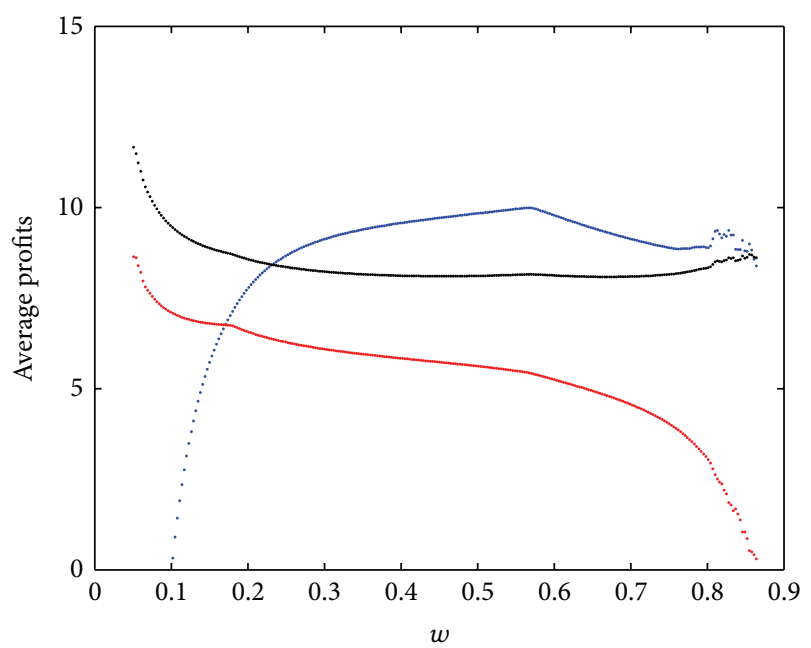

FIGURE 16: Effects of assigning weight $w$ on average profits.

5.2. The Effects of Assigning Weight $w$ on Profits and Prices. Next, we will discuss the effects of assigning weight $w$ on profits and prices; the values of the parameters are the same as above in (18), and $\alpha=\beta=0.3$.

The effects of assigning weights $w$ and $1-w$ on the three firms' profits can be shown in Figure 15. In Figure 15, blue set of points denotes $\pi_{1}(t)$, red set of points denotes $\pi_{2}(t)$, and black set of points denotes $\pi_{3}(t)$. Figure 16 shows the average profits in 100 games when the system is in all different states.

In Figure 15, if $w$ is too small $(w<0.18)$ or too large $(w>0.57)$, all the firms' profits will lose stability and even fall into chaos. In the stable interval of $w$, about $(0.18$, $0.57)$, team firm's profits increase (decrease) with the increase (decrease) of their own assigning weight. Profits of firm 3 remains relatively stable.

In Figure 16, by comparison, we can find that, with increase of $w$, profits of firm 1 increase first and then decrease after the bifurcation point (0.57), profits of firm 2 decrease,

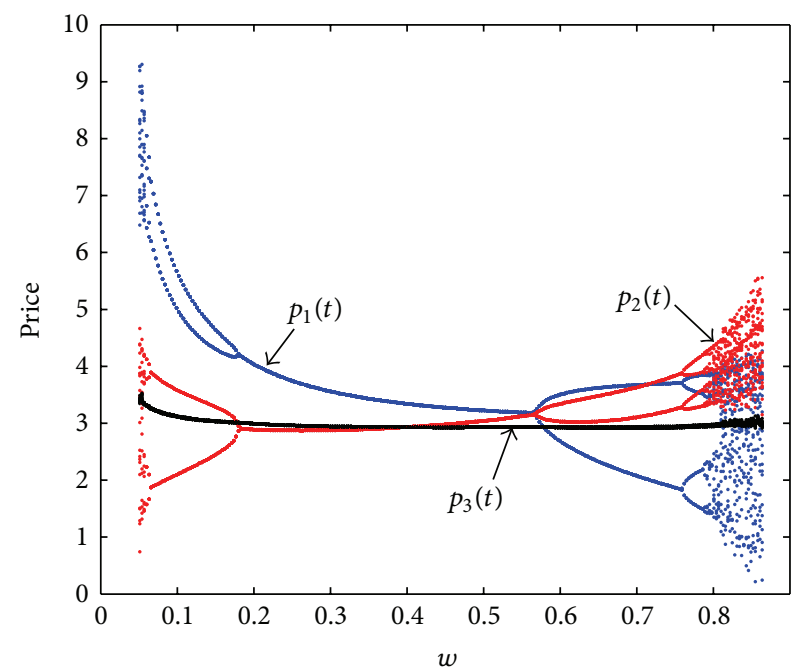

FIGURE 17: Effects of assigning weight $w$ on prices.

and profits of firm 3 decrease first and then increase after the bifurcation point (0.57).

We can get the following results from Figures 15 and 16.

(1) If the strengths of the two firms in the cooperative team have a big gap, the market will experience cyclical shock and fall into chaos in the competition.

(2) In the stable interval of $w$, term members' profits and their own assigning weight have the same trends, so, in order to obtain more profits, firms in the cooperative team should strive to improve their own strengths.

(3) Chaos resulting from $w$ is not necessarily bad for term members but is conducive to firm 3 .

The prices of the three oligopolists with different $w$ are shown in Figures 17 and 18. We can find the following results.

(1) If $w$ is too small $(w<0.18)$ or too large $(w>0.57)$, all the firms' prices will lose stability and even fall into chaos.

(2) When $w \in(0.18,0.57)$, term members' prices and their own assigning weight have the contrary trends; that is, firm's price increases (decreases) with the decreasing (increasing) of their own assigning weight. Prices of firm 3 remain stable.

\section{Basins of Attraction of the System}

In order to investigate the impact of price adjustment speed on the attraction domain, we introduce basins of attraction which are the sets of initial prices.

By fixing the system parameters as mentioned above, let $w=0.45$, let $v=0.5$, let $p_{3}=1$, and let $(\alpha, \beta)=(0.3,0.3)$, $(0.4,0.4),(0.5,0.5)$, respectively; three basins of attraction about $\left(p_{1}, p_{2}\right)$ of the system are shown in Figures 19, 20, and 21 in which the green set of points denotes attraction domain, 


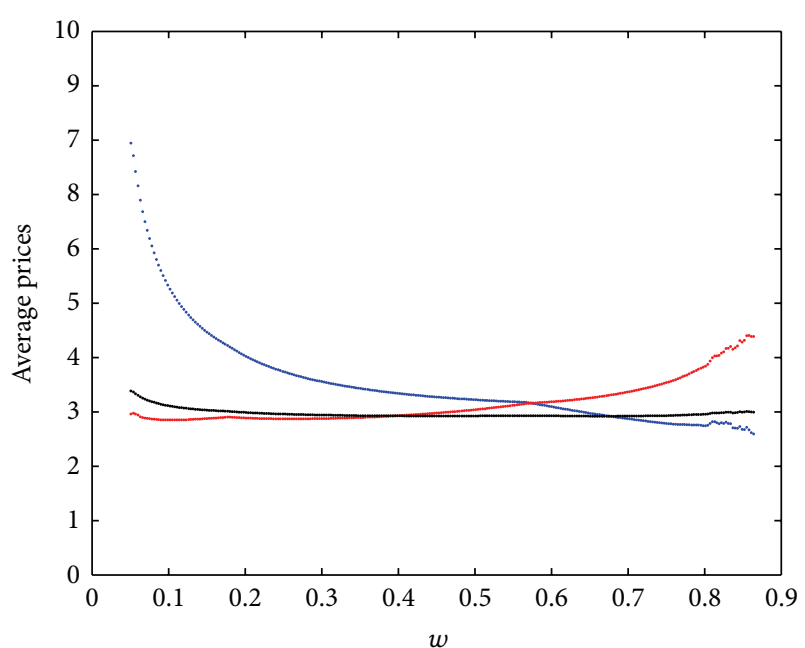

FIGURE 18: Effects of assigning weight $w$ on average prices.

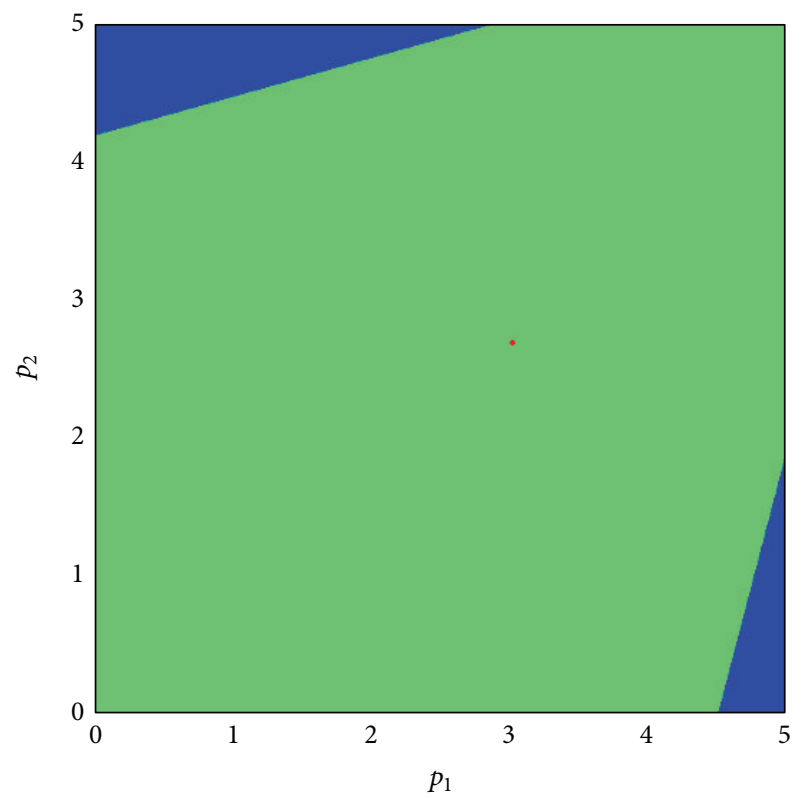

FIGURE 19: Basin of attraction when $(\alpha, \beta)=(0.3,0.3)$.

the red set of points denotes attractor, and the blue set of points denotes escape area.

The attraction domain is the set of initial prices where the same attractor will emerge after iteration if the initial prices are taken from the attraction domain. If the attractor is one equilibrium point, from an economic point of view, the corresponding attraction domain is a safe region. That means if the initial prices of two sides is in the safe region, the system will remain stable after iteration. If the initial price is in the escape area, the system will fall into divergence at last.

In Figure 19, $\alpha=0.3$ and $\beta=0.3$; according to Figure 2, the system is in stable state; we can see that attraction domain is an irregular hexagon, and it is a safe region. In Figure 20, $\alpha=0.4$ and $\beta=0.4$; according to Figure 2, the system is in period- 2 state. The attraction domain is also an

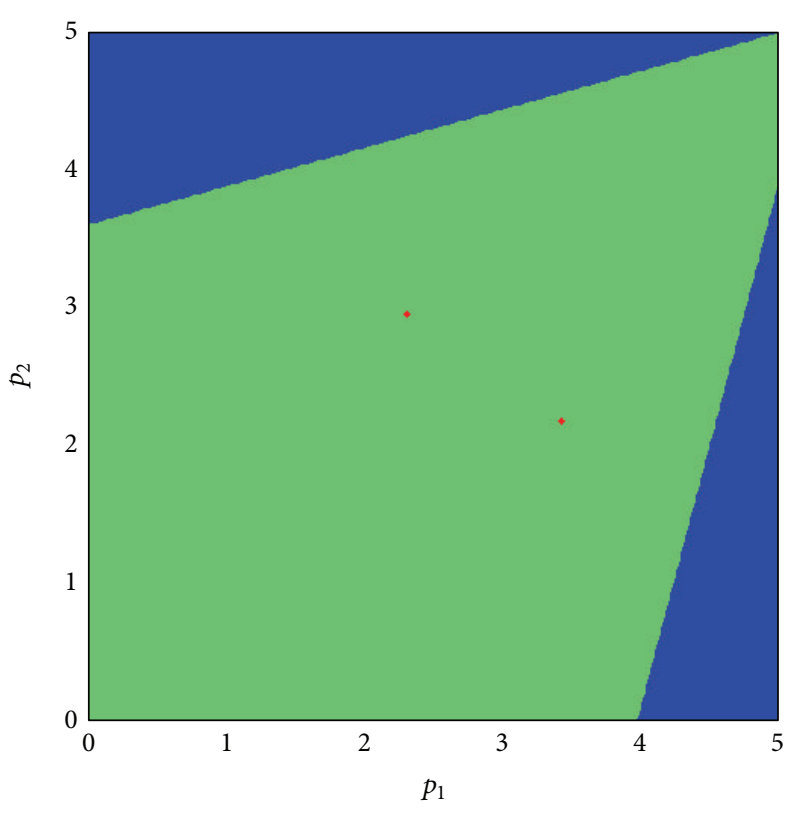

FIGURE 20: Basin of attraction when $(\alpha, \beta)=(0.4,0.4)$.

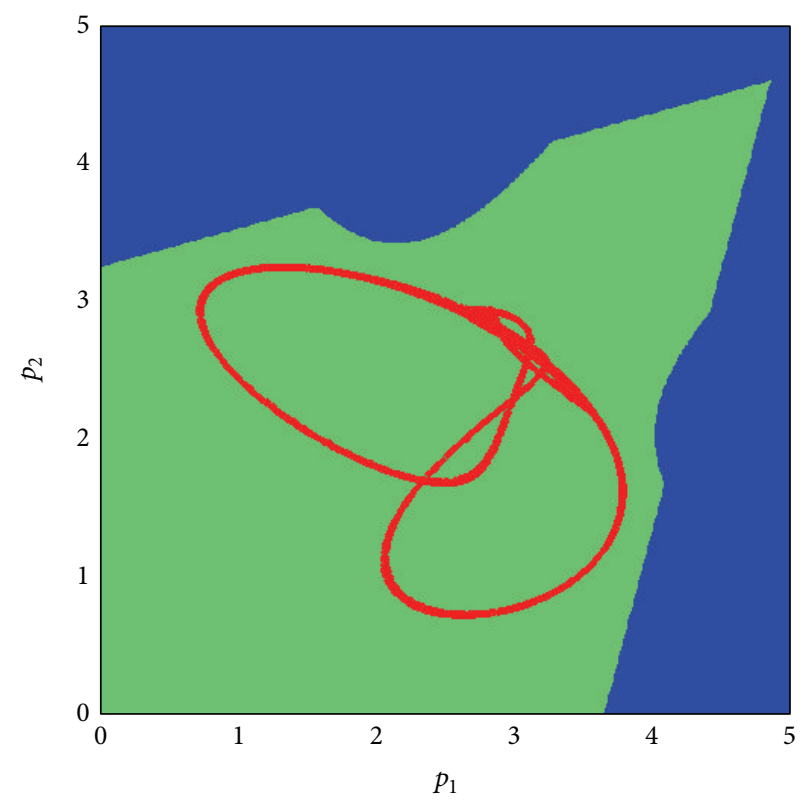

Figure 21: Basin of attraction when $(\alpha, \beta)=(0.5,0.5)$.

irregular pentagon area. The attractor is a two-period cycle which means that if the initial prices of two sides are in this attraction domain, then prices will oscillate between two points at last. In Figure 21, $\alpha=0.5$ and $\beta=0.5$; according to Figure 2, the system is in chaotic state. The prices will converge to a chaotic attractor if the initial prices are in the attraction domain of Figure 21.

Figures 22(a)-22(d) show the prices difference $\left(\Delta p_{i}\right)$ changes with increasing of games. Figures 22(a)-22(d) can be regarded to verify Figures 19-21. 


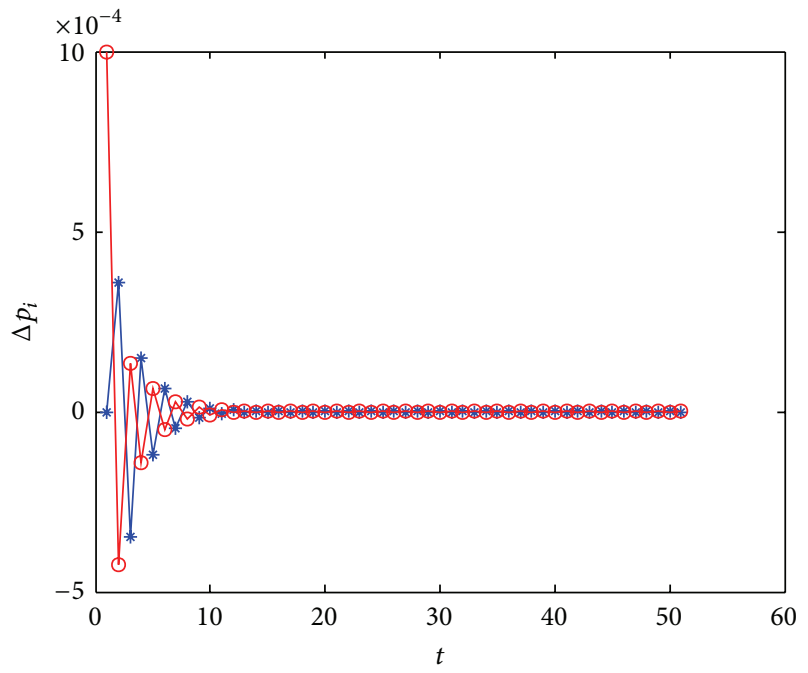

(a)

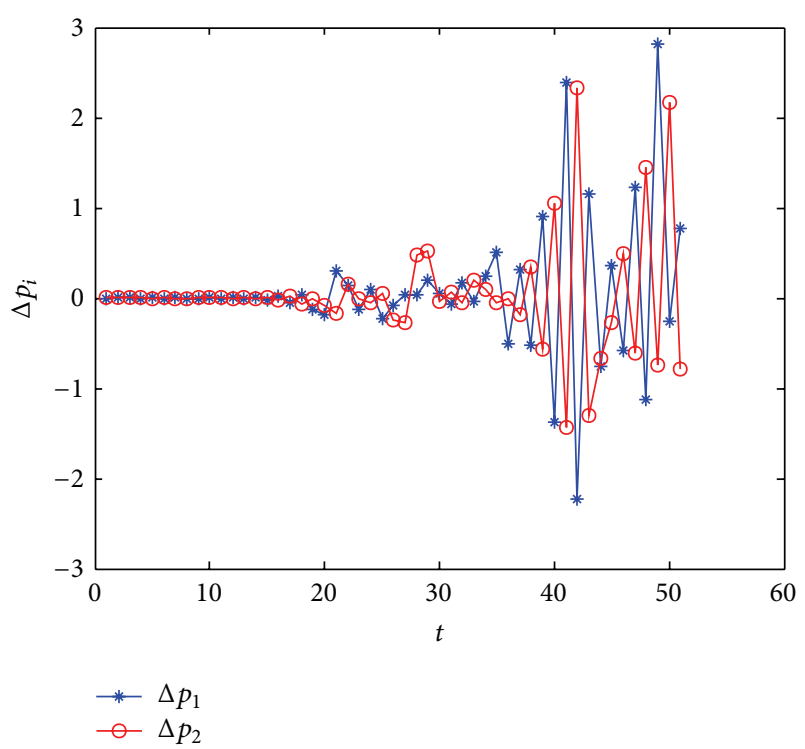

(c)

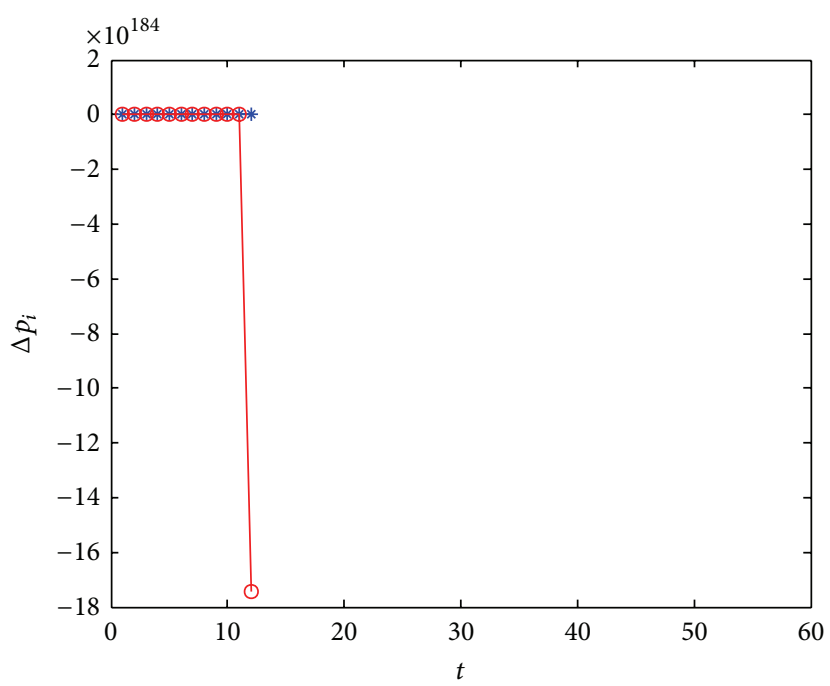

(b)

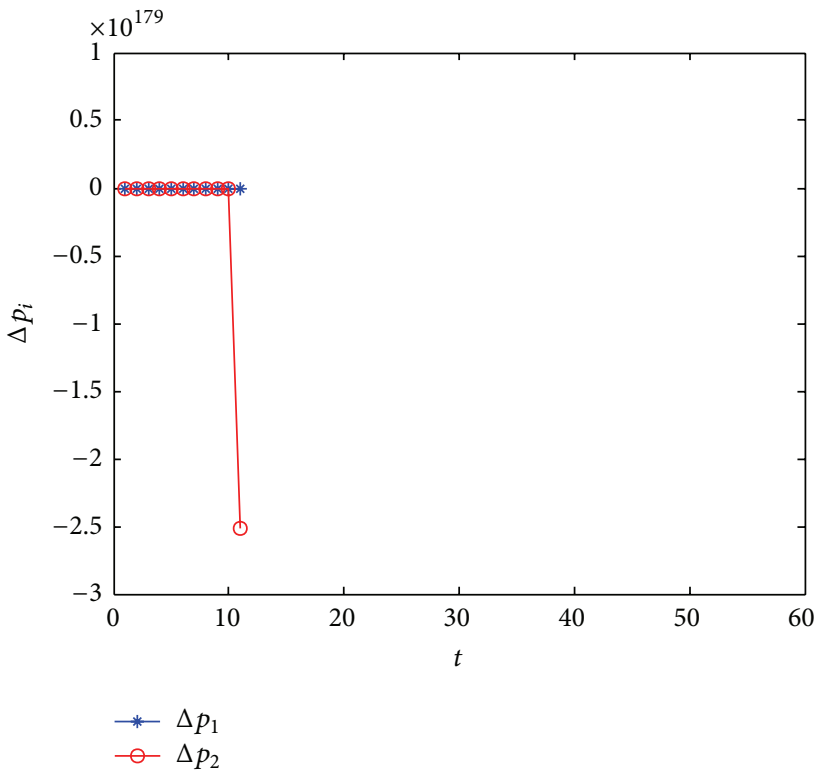

(d)

Figure 22: (a) Difference $\left(\Delta p_{i}\right)$ changes with increasing of games when $(\alpha, \beta)=(0.3,0.3)$. (b) Difference $\left(\Delta p_{i}\right)$ changes with increasing of games when $(\alpha, \beta)=(0.3,0.3)$. (c) Difference $\left(\Delta p_{i}\right)$ changes with increasing of games when $(\alpha, \beta)=(0.5,0.5)$. (d) Difference $\left(\Delta p_{i}\right)$ changes with increasing of games when $(\alpha, \beta)=(0.5,0.5)$.

In Figure 22(a), $(\alpha, \beta)=(0.3,0.3)$, initial prices $A\left(p_{1}\right.$, $\left.p_{2}\right)=(3,3)$, and $B\left(p_{1}, p_{2}\right)=(3,3.001)$. As can be seen in Figure 22(a), $\Delta p_{i}$ tends to be 0 after a number of games. Notice that points $A$ and $B$ are in the domain of attraction of Figure 19, so price will converge to the Nash equilibrium price after iteration, which is consistent with Figure 22(a).

In Figure 22(b), initial prices $C\left(p_{1}, p_{2}\right)=(1,5)$ and $D\left(p_{1}\right.$, $\left.p_{2}\right)=(1,5.001)$, when $(\alpha, \beta)=(0.3,0.3)$. As can be seen in Figure 22(b), the system is divergent after iteration. Points $C$ and $D$ are in the escape area of Figure 19, so prices will be divergent which is consistent with Figure 22(b).

In Figure 22(c), $(\alpha, \beta)=(0.5,0.5)$, initial prices $E\left(p_{1}\right.$, $\left.p_{2}\right)=(1,1)$, and $F\left(p_{1}, p_{2}\right)=(1,1.001)$. As can be seen in
Figure 22(c), we can see that when $p_{2}$ changes a little and $p_{1}$ stay unchanged, the price will have distinct changes. Notice that $E$ and $F$ are in the domain of attraction of Figure 21. It fully manifests the sensitive dependence on the initial conditions of system.

In Figure $22(\mathrm{~d})$, initial prices $G\left(p_{1}, p_{2}\right)=(1,4)$ and $H\left(p_{1}\right.$, $\left.p_{2}\right)=(1,4.001)$, when $(\alpha, \beta)=(0.5,0.5)$. As can be seen in Figure 22(d), the system is divergent after iteration. Points $G$ and $H$ are in the escape area of Figure 21, so price will be divergent which is consistent with Figure 22(d).

From the comparison of Figures 19, 20, and 21, we find that the attraction domain reduces with increase of price adjustment speed under the conditions that the initial prices 
of the third firm are fixed. From an economic perspective, with increase of price modification speed of firms 1 and 2, the two firms' initial prices should be lower in order to maintain a stable market. Because prices decision in every time is the initial value of the following series of games, firms cannot make arbitrary decisions in every time.

\section{Conclusion}

In this paper, we have studied a Bertrand Triopoly model with team-game. The existence and local stability of the Nash equilibrium are analyzed. The stable regions show that players should control their price adjustment speed to maintain the market stable. If one firm is stronger than the other in the cooperative team, the range of their price adjustment speed is smaller.

With the increase of price modification speed, the system will fall into chaos via period-doubling bifurcations and Neimark-Sacker bifurcations. Chaos resulting from adjustment speed is harmful to all the players. The effects of assigning weight $w$ on profits show that chaos resulting from $w$ is conducive to firm 3 .

Using basins of attraction, we have found that the attraction domains become smaller with increase of price modification speed, and, in order to maintain market stable, two team firms' prices must be kept within a certain range.

\section{Conflict of Interests}

The authors declare that they have no competing financial interests.

\section{Acknowledgments}

The authors would like to thank the reviewers for their careful reading and for providing some pertinent suggestions. The research was supported by the National Natural Science Foundation of China (no. 61273231) and Doctoral Fund of Ministry of Education of China (no. 20130032110073).

\section{References}

[1] H. Bester, "Bertrand equilibrium in a differentiated duopoly," International Economic Review, vol. 33, no. 2, pp. 433-448, 1992.

[2] J. Zhang, Q. Da, and Y. Wang, "The dynamics of Bertrand model with bounded rationality," Chaos, Solitons and Fractals, vol. 39, no. 5, pp. 2048-2055, 2009.

[3] J. Peng, Z. H. Miao, and F. Peng, "Study on a 3-dimensional game model with delayed bounded rationality," Applied Mathematics and Computation, vol. 218, no. 5, pp. 1568-1576, 2011.

[4] J. H. Ma and K. F. Wu, "Complex system and influence of delayed decision on the stability of a triopoly price game model," Nonlinear Dynamics, vol. 73, no. 3, pp. 1741-1751, 2013.

[5] L. Fanti, L. Gori, C. Mammana, and E. Michetti, "The dynamics of a Bertrand duopoly with differentiated products: Synchronization, intermittency and global dynamics," Chaos, Solitons \& Fractals, vol. 52, no. 1, pp. 73-86, 2013.

[6] J. Zhao, J. Wei, and Y. Li, "Pricing decisions for substitutable products in a two-echelon supply chain with firms' different channel powers," International Journal of Production Economics, vol. 153, pp. 243-252, 2014.

[7] B. C. Giri and S. Sharma, "Manufacturer's pricing strategy in a two-level supply chain with competing retailers and advertising cost dependent demand," Economic Modelling, vol. 38, pp. 102111, 2014.

[8] E. Ahmed and A. S. Hegazi, "On dynamical multi-team and signaling games," Applied Mathematics and Computation, vol. 172, no. 1, pp. 524-530, 2006.

[9] M. F. Elettreby and S. Z. Hassan, "Dynamical multi-team Cournot game," Chaos, Solitons \& Fractals, vol. 27, no. 3, pp. 666-672, 2006.

[10] Z. W. Ding, Q. L. Hang, and L. X. Tian, "Analysis of the dynamics of Cournot team-game with heterogeneous players," Applied Mathematics and Computation, vol. 215, no. 3, pp. 1098$1105,2009$.

[11] I. Manimehan and P. Philominathan, "Composite dynamical behaviors in a simple series-parallel LC circuit," Chaos, Solitons \& Fractals, vol. 45, no. 12, pp. 1501-1509, 2012.

[12] J. A. C. Gallas, "The structure of infinite periodic and chaotic hub cascades in phase diagrams of simple autonomous flows," International Journal of Bifurcation and Chaos in Applied Sciences and Engineering, vol. 20, no. 2, pp. 197-211, 2010.

[13] Y. A. Kuznetsov, Elements of Applied Bifurcation Theory, Springer, New York, NY, USA, 2nd edition, 1994. 


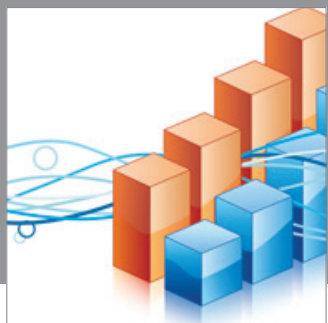

Advances in

Operations Research

mansans

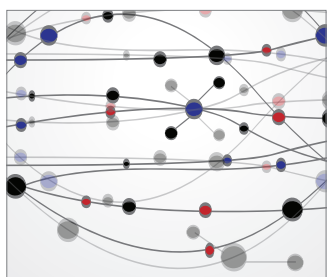

The Scientific World Journal
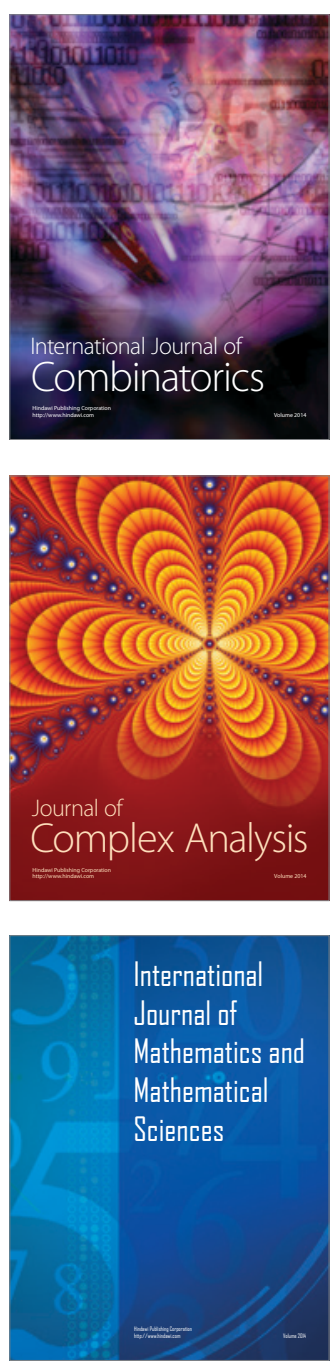
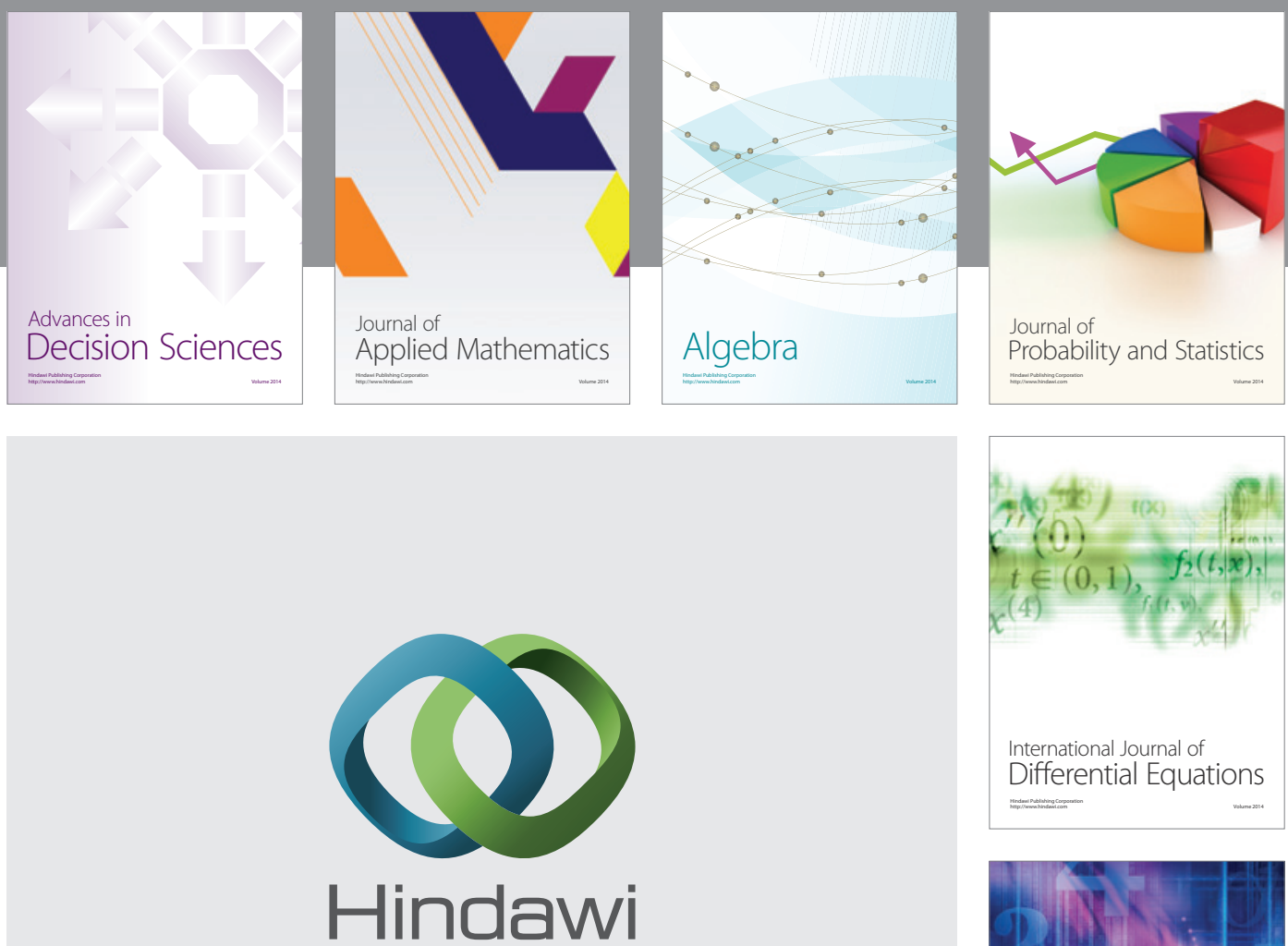

Submit your manuscripts at http://www.hindawi.com
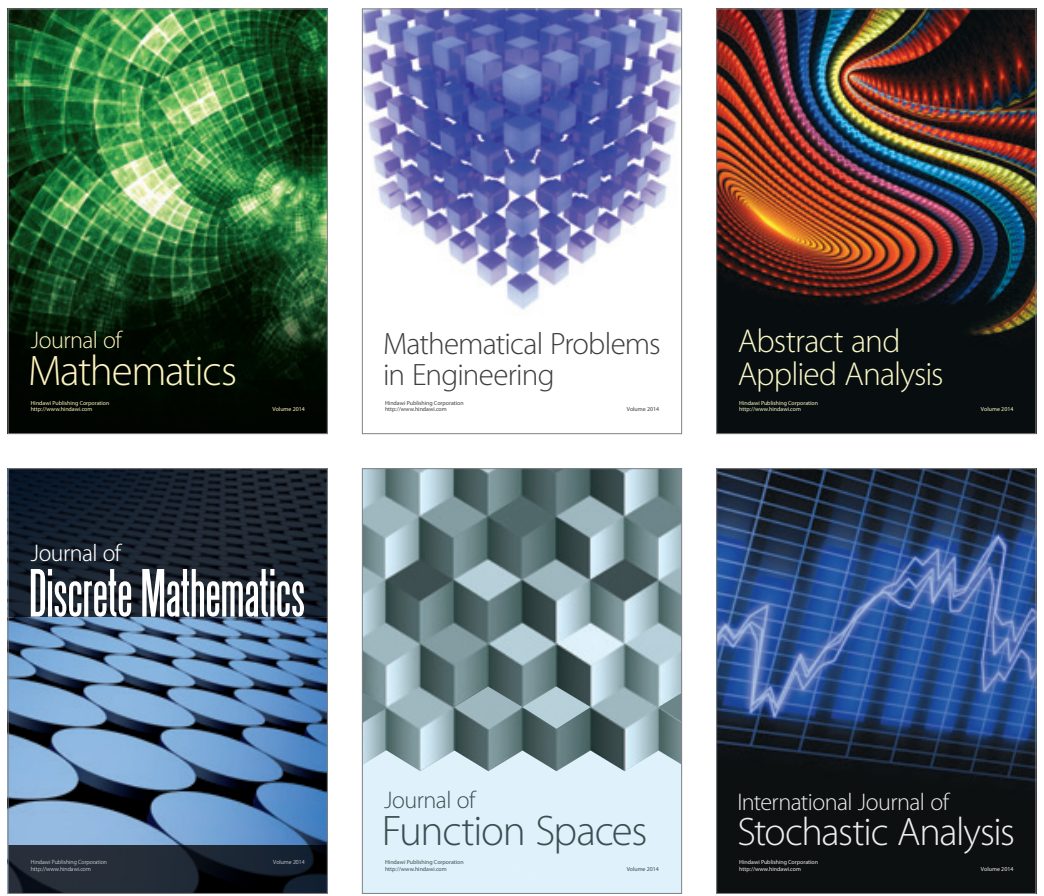

Journal of

Function Spaces

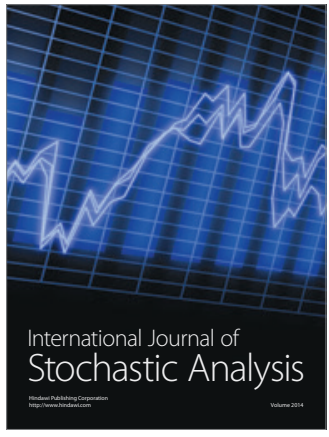

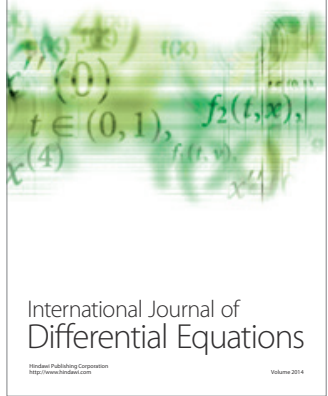
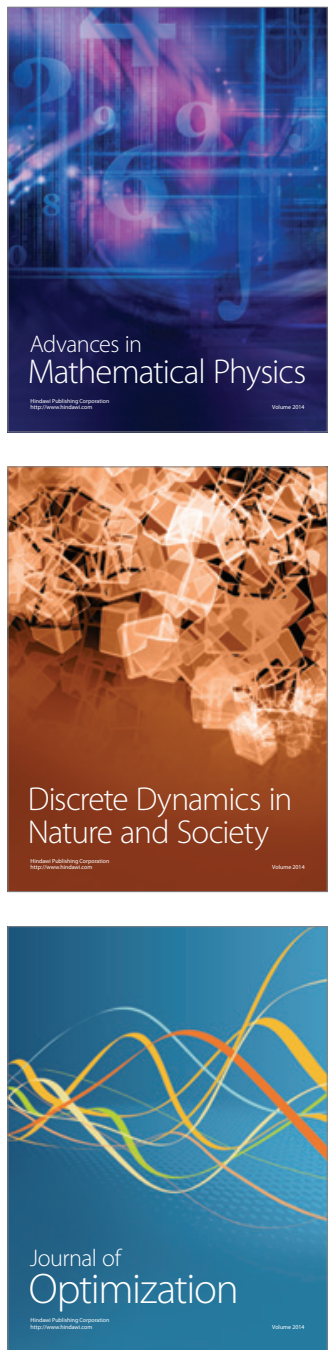